管理·

\title{
加拿大自然保护区规划的启迪
}

\author{
许学工 \\ ( 北京大学城市与环境学系, 北京 100871)
}

\begin{abstract}
摘要: 为了更好地与国际接轨, 搞好自然保护区的管理工作, 我们需要学习其他国家的先进经验。本文重点介绍加 拿大自然保护区规划方面的典型经验,包括系统规划、综合管理规划、资源管理规划、服务规划、行动规划, 以及各 种规划之间的关系,并提出了对我们的启迪与可借鉴之处。
\end{abstract}

关键词：自然保护区，规划，加拿大

中图分类号:X36文献标识码 :B 文章编号 : 1005-0094(2001)03-0306-04

\section{Enlightenment from planning of natural protected areas in Canada}

XU Xue-Gong

Department of Urban and Environmental Sciences, Peking University , Beijing 100871

\begin{abstract}
Natural protected areas management holds a unique position within the field of resource and environment. Since the 1990 s and with the increasing acceptance of the idea of sustainable development , China has made great progress in nature protection. However, despite the rapid increase in both number and area of natural protected areas, there still exist problems in their management. It is necessary to study and learn advanced managing experiences from other countries. This paper introduces the planning of National Protected Areas in Canada, including system planning, management planning, resources management planning, service planning and action planning, as well as the relationship of many types of planning. Then brings forward what we gain edification and can use for reference ,so as to promote jointing with international conducts and make well natural protected areas management in China.
\end{abstract}

Key words : natural protected areas, planning, Canada

自然保护区在资源与环境领域中占有独特的地位。为 了保护生物多样性, 维护自然的发展进程,使我们及后代具 有永续的资源和良好的生态环境，自然保护区的建立和管理 成为一项伟大的、富于挑战性的事业。

20 世纪 90 年代以来, 可持续发展的观念逐渐深入人 心，我国的自然保护事业也有了长足的进展。与国际上广义 的自然保护区 (Natural protected areas) 概念相对应, 中国自 然环境和自然资源的就地保护系统主要有各级自然保护区、 森林公园及风景名胜区等, 近年来在数量和面积上增长很 快, 但同时也存在着管理上的问题。我们迫切需要学习和引 进其他国家保护区管理的先进经验和有效机制, 提高我们的 综合管理水平。

加拿大是一个广衣而美丽的国家, 在保护区管理方面做 了许多出色的工作,有许多先进的经验可资借鉴。本文重点 介绍其规划方面的经验，以期为中国的自然保护事业提供参
考。

\section{1 加拿大自然保护区概况}

本文所指的自然保护区是广义的, 即 Natural Protected Areas。加拿大的自然保护区包括一个庞大的系统, 在国家 这一层次有国家公园、国家海洋保护区、国家野生动植物保 护区、国家候乌禁猎区、国家首都保护地、加拿大遗产河流系 统等; 在省级有省立公园、荒野保护区、省立自然保护区 ( Nature Reserve)、乌类禁猎区和生态保护区等, 还有地区级和地 方级的保护区。我们国内通常所称的自然保护区是狭义的, 即 Nature Reserve, 这种狭义的保护区只是加拿大自然保护 区系统中的一个类型,也是世界自然保护联盟 (IUCN) 保护 区分类系统中的一个类型。

加拿大的自然保护区管理有三个基本理念“: 生态完整 性” “ 纪念完整性”和 可持续发展”。生态完整性不仅指保 
护某一生态系统完整无损, 还要保证与其毗邻的生态系统处 于完整的联系与平衡之中。纪念完整性适用于自然遗产和 文化遗产地, 要将历史的发生和发展有效地呈现给公众, 使 遗产价值受到尊重。可持续发展是布伦特兰委员会所使用 的概念, 已取得世界各国的共识, 而早在布伦特兰委员会之 前, 加拿大的《国家公园法案》就要求对公园的利用必须控 制在 不损害后代人享用”,成为保护区管理的一个基本准 则。

加拿大的国家公园要经议会批准立法建立, 同样对其管 理规划也有法律要求。加拿大遗产河流经提名和认定而建 立, 但在认定之前必须提交管理规划。其他类型的保护区对 规划工作也很重视, 但除国家公园之外, 对规划不作法律要 求。

1990 年, 加拿大政府颁布了《加拿大的绿色规划》( Canada's Green Plan)。这是一个将环境视为相互关联之整体 的综合性规划,也是一个最重要的环境行动规划, 该规划提 出了若干目的、相关的目标及进度表, 其中 目的 3 加拿大 特有空间和物种的保护”与保护区直接有关, 这方面的具体 目标有 将加拿大 $12 \%$ 的国土作为保护空间;至 2000 年完成 国家公园系统的建设，维护并增进加拿大野生动物和植物的 健康与多样性; 加拿大历史遗产的纪念和保护 (Government of Canada ,1990)。《加拿大的绿色规划》提出的框架、目的 和目标促进了加拿大自然保护区的建立和规划。

下面以国家公园为例，分析加拿大自然保护区的规划情 况。

\section{2 规划类型}

加拿大国家公园的规划类型主要包括:系统规划、管理 规划、自然资源管理规划、服务规划和行动规划等, 对其要 点分述如下：

\section{1 系统规划}

系统规划是一种综合性的宏观规划，其内容涵盖公园的 建立、可能的未来公园及它们对所在区域自然和文化特征的 代表性，旨在为保护国家级的自然遗产设计一个系统，建立 一个框架, 并确定一个长远的目标。《国家公园系统规划》 制定了加拿大的陆地自然区划, 并对 39 个陆地自然区域以 及每个区域中国家公园的建立状况和潜力进行阐述，该规划 的目标是在每一个自然区域中至少建立一个国家公园 (Parks Canada，Canadian Heritage ,1997)，国家公园的选建可 以从系统规划获得指导。

\section{2 管理规划}

管理规划针对某一个国家公园制定, 其目标是提供一种 能够涵盖全公园各层次方针政策的综述性文件。它是管理 者必不可少的指南, 同时也使公众清晰了解政府对每个公园 的政策观点。加拿大公园局把管理规划看作是责任部长就 国家公园的利用与保护向公众所作的承诺。管理规划包含
如下内容: 确定管理目标并详尽说明公园将采取何种措施来 保护和体现本区域的自然与文化特征，详细说明公园采取何 种类型与级别的资源保护与管理措施来保持公园的生态完 整性和有效管理公园的文化资源;公园分区确定旅游设施、 活动和服务的类型、特点及位置; 确定目标群。

在详细程度上，管理规划属于综合、概括的总体规划，它 为顺利实施管理和制定后续的详细规划搭建起一个框架。 在该规划的制定过程中, 要对多种规划理念进行选择, 要体 现管理层的各项决策, 同时要有公众的参与。通常情况下, 土地交移加拿大公园局管理和控制后, 就立即开始编制国家 公园的管理规划。按照规定, 在议会法案宣布建立一个新国 家公园之后的 5 年内, 责任部长要审定批准该公园的管理规 划并将其提交给议会。以后每 5 年, 部长都须对管理规划进 行检查和修订并再次向议会提交 (Canadian Heritage ,1994)。

\section{3 资源管理规划}

继管理规划之后, 要针对特殊问题制定一系列更加详细 的政策。资源管理规划的目标是明晰管理行为的责任与程 序, 以解决在保护区管理规划中所阐述的资源问题。

本规划将公园管理规划的总体目标和保护原则与包括 特定资源、活动或场址等在内的各种特殊问题联系起来, 如 濒危物种、植被、鱼类和野生动物、古生物资源、火灾管理等。 资源管理规划通常由公园管理人员来制定, 而由公园所在地 区的职员和其他专家进行必要的协助。为了确保资源管理 规划的连续适用性，应当按照监测规范对其进行定期检查。

\section{4 服务规划}

服务规划是游客活动管理过程的一部分。在符合资源 保护与纪念遗址保护规定的同时，此规划通过市场定位，综 合考虑公园游客的需求、期望和满意度来制定。服务规划要 确定国家公园游览项目的方向和优先顺序, 将管理规划中概 念性的东西转化为提供给公众的切实的服务, 以及相应的执 行策略。

无论是制定服务于游客的长期战略还是即时决策，公园 服务规划都不失为一种有效的工具，规划本身应当具有决策 倾向性, 能够直接与其他的决策系统相联系。规划必须对公 园当前的情形和服务状况加以分析，以使公园管理者明确自 己的立足点, 从而在规划今后 $3 \sim 5$ 年的服务项目时有一个 理性的依据。服务规划也包含日后的执行、监控和修正( Canadian Parks Service , Environment Canada ,1988)。

\section{5 行动规划}

行动规划是为实现管理规划所作的行为计划，它为支持 和实现保护区纲要所设立的目标而制定必要的措施。本规 划用于组织短期活动和现时活动。许多短期活动被安排在 同时进行, 而一些较早行动的结果将直接支持其他必要的后 续行动。公园在最初几年会有重要的进展, 但还须有后续的 行动来维护自然遗产区并培育有助于实现长期保护目标的 伙伴关系。行动规划中的每一项行动都有具体的目标, 所有 
的行动形成一个进度表, 可以按照规划对这些行动进行操作 和检查。

\section{3 各种规划类型的关系}

系统规划、综合的管理规划、资源管理规划、服务规划、 行动规划是公园和保护区规划的主要阶段。在一个完备的 规划系统中还有其他多项专门规划，如子行动/分区规划、设 备/景点规划、媒体/设计与发展规划、以及营业规划等。我 们可以通过国家公园的规划过程来了解它们彼此之间的关 系。(图 1)

如框图所示, 公园系统规划为高层次的决策服务, 在此
规划中对候选的国家公园进行评价; 公园管理规划处于核心 地位，在此规划中体现和贯彻国家公园的方针; 框图左侧的 资源管理和右侧的游客行为管理研究为上述两个决策结构 提供信息, 并在公园管理规划的指导下分别形成资源管理规 划和公园服务规划;自公园建立始，管理规划及周期性的检 查评估就驱动了资源管理和游客利用管理过程;子行动/分 区规划和设备/景点规划是公园管理规划下的中、小尺度和 短期行动计划。依靠上述各项规划的有效实施, 公园业务得 以运转并实现国家公园保护与发展的长期目标。

通过国家公园的规划系统，加拿大自然保护区的规划管 理可见一斑。当然, 其他类型的保护区在规划中还有它们的
自然与文化资源

管理程序输入

Natural and Cultural Resource

Management Processes Input
旅游者行为

规划过程

PLANNING PROCESS
管理程序输入

Visitor Activity Management

Processes (VAMP) Input

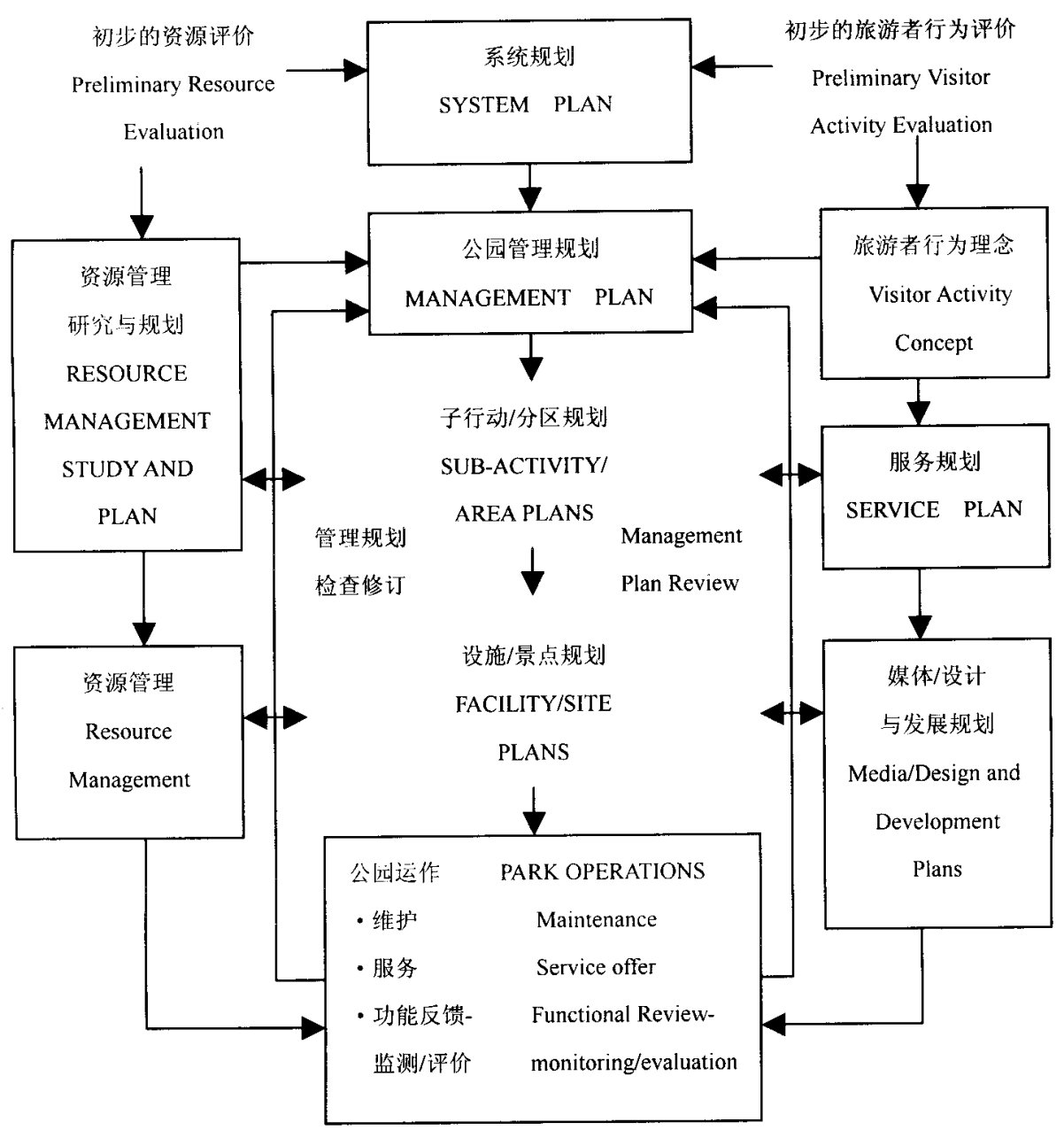

图 1 国家公园规划过程一一表现各种规划之间的关系

Fig. 1 National Park Planning Process—Showing the relationship of many types of planning ( Source :Canadian Parks Service , Environment Canada ,1998;Payne \& Graham ,1993) 
个性特点。

\section{4 启迪与借鉴}

分析加拿大自然保护区规划方面的经验，可以得到以 下的启迪和借鉴 :

(1) 完备的规划系统是加拿大国家公园给予我们的深刻 印象。国家公园系统规划提供全国的宏观指导框架和长远 目标，总体性的管理规划确定一个国家公园的目标和方针政 策，详细的资源管理规划、服务规划和行动规划针对具体问 题、具体时段制订可操作性的项目和活动计划，这样一个规 划系统的实施及周期性的检查评估驱动了国家公园的运作 过程，使规划真正起到指导和计划作用，而不仅仅是 纸上画 画墙上挂挂” 的花架子。目前我国的自然保护区和风景名 胜区在高层次的系统规划和较低层次的资源、服务详细规划 以及中、小尺度的行动规划方面比较薄弱, 可以从加拿大的 做法中得到借鉴。

(2) 加拿大对国家级的自然保护区要求特别严格, 其 管理规划” 相当于我们的总体规划。加拿大对国家公园的 管理规划有制订、检查和更新的法规要求，把管理规划看作 是责任部长就国家公园的利用与保护向公众所作的承诺。 虽然我们许多国家自然保护区、风景名胜区与森林公园已经 制定或准备制订总体规划，但没有提到这样的高度，也没有 严格的法规要求, 更缺乏检查和更新机制。加拿大的做法是 值得我们借鉴的。

(3) 加拿大国家公园管理规划的制定和实施是部长的职 责,同时要求管理人员、职员们多学科知识的配合与公众的 参与。公众参与可以帮助规划者认识和解决国家公园自然 保护与地区发展之间的矛盾和问题，寻求解决矛盾的途径; 另一方面也可以籍此提高公众的自然保护意识和责任感,为 规划的实施打下基础。

(4) 加拿大保护区的三个基本理念是“: 生态完整性”、 “纪念完整性”、“可持续发展”。在保证生态完整性和纪念 完整性的前提下制定服务规划,努力满足游客的需求和期 望。目前我国许多森林公园、风景名胜区，以至自然保护区
都在制订生态旅游规划，一定不要忘记其最主要的宗旨是自 然遗产和生态的保护，必须规划好保护区内部的功能分区和 保护措施。生态旅游依赖于高品质的自然环境, 其目的是要 提高公众的生态意识和环境意识, 面对经济利益的驱动, 管 理者应当保持清醒的头脑并在规划中建立一种自律的平衡。 在我国，宣传广义自然保护区的概念，使森林公园和风景名 胜区的保护职责得到强化是必要的。

(5)“加拿大的绿色规划”作为政府的国家环境行动规 划对自然保护区的建立和规划起到重要的推动作用。其特 点是将环境作为整体来看待, 并对每一方面有明确的目的、 指标和进度要求, 起到国家的导向作用。而且通过绿色规划 的颁布与实施，极大地提高了全民的环境意识，这对我们也 有借鉴意义。

“他山之石,可以攻玉”,我们可以借鉴加拿大的先进经 验，立足于中国国情并着眼于与国际接轨，搞好中国的自然 保护区管理。

\section{参考文献}

Canadian Heritage, 1994. Parks Canada Guiding Principles and Operational Policies. Ottawa: Minister of Supply and Services Canada, $25 \sim 45$

Canadian Parks Service, Environment Canada, 1988. Getting Started - A guide to service planning. Ottawa: Minister of Supply and Services Canada, $12 \sim 19$

Government of Canada, 1990. CANADA'S GREEN PLAN Canada's Green Plan for a healthy environment. Ottawa: Minister of Supply and Services Canada, $12 \sim 14$

Parks Canada, Canadian Heritage, 1997. National Parks System Plan (third edition). Ottawa: Minister of Public Works and Government Services Canada, $4 \sim 10$

Payne R J and Graham R, 1993. Visitor planning and management in parks and protected areas. In: Dearden P, Rollins $\mathrm{R}$ (eds.), Parks and Protected Areas in Canada - Planning and Management. Toronto, ON: Oxford University Press, $211 \sim 224$ 